\title{
Teaching Climate Change Science to High School Students Using Computer Games in an Intermedia Narrative
}

\author{
Glenn Gordon Smith ${ }^{1 *}$, Metin Besalti ${ }^{1}$, Molly Nation ${ }^{2}$, Allan Feldman ${ }^{1}$, Katie Laux ${ }^{1}$ \\ ${ }^{1}$ University of South Florida, USA \\ ${ }^{2}$ Florida Gulf Coast University, USA
}

Received 18 May 2018 - Revised 26 October 2018 • Accepted 13 December 2018

\begin{abstract}
We explored how computer games developed as part of an innovative set of climate change education materials helped students learn and gain interest in global climate change (GCC) science by making it personally relevant and understandable. This research was conducted in a public school district in the southeastern United States. The curriculum, Climate Change Narrative Game Education (CHANGE), used a local, place-based approach using scientific data gathered from the Gulf of Mexico coast and incorporated (a) computer games, (b) a scientifically web-based science fiction novel about future Gulf coast residents, and (c) hands-on laboratory activities. This paper focuses on how the computer games affected students' learning, validity of their beliefs about GCC, and understanding of the effects of GCC on the region's sea level and storms. The data collected included students' exam scores, and surveys about student perceptions of climate change science and perceptions of the materials. On exam questions related to GCC science, students who participated in the CHANGE curriculum scored significantly higher than their peers who did not. Also, their beliefs about GCC increased in validity. The nature and design of the computer games had a strong impact on students' understanding of sea level rise and storms.
\end{abstract}

Keywords: computer games, climate change science, global warming, high-school, place-based

\section{INTRODUCTION}

There is international consensus among scientists that global climate change (GCC) is one of the most significant environmental challenges we face (IPCC, 2013). Two of the major effects of GCC are: (1) the rising of sea level due to thermal expansion of the oceans and melting of continental ice, and (2) anomalous and extreme weather events. Both of these are worrying to inhabitants in the southeastern United States with its long coastlines and extensive low-lying barrier islands. In this region, small changes in sea level cause extensive social impacts and economic losses (Galindo-Gonzalez et al., 2011). These areas are vulnerable to hurricanes and associated storm surge, both of which are likely to become more frequent and intense as the Earth continues to warm. It is imperative that students become aware of how this will affect the built environment (where we live) by learning the science behind GCC and what can be done to mitigate these effects.

Climate change is an important issue and its presence in science curricula is increasing. This has been described as a greening of the curriculum as more environmentally focused content is introduced (Junyent \& de Ciurana, 2008). Although GCC is included in the 2013 Next Generations State Standards (NGSS), the United States was one of the last Western countries to adopt climate change as a part of its national curriculum. That said, Bentley, Ebert, and Ebert (2007) found that regardless of the inclusion of climate change in the national standards, many teachers are still not teaching the issue.

(C) 2019 by the authors; licensee Modestum Ltd., UK. This article is an open access article distributed under the terms and conditions of the Creative Commons Attribution License (http://creativecommons.org/licenses/by/4.0/). \glenns@usf.edu (*Correspondence) $\nabla$ metinbesalti@mail.usf.edu $\square$ mnation@fgcu.edu 


\section{Contribution of this paper to the literature}

- Based on scientific consensus, human-caused climate change is one of the greatest challenges currently facing humankind. Yet, most science teachers do not formally teach climate change science.

- Climate change science is difficult to teach and hard for high school students to learn, because it is interdisciplinary, with most extreme effects in the future and is often discussed in global terms.

- We investigated how a climate change science curriculum including interdisciplinary science, a local, placebased approach and impacted high school student learning of climate change science, their beliefs, and particularly how educational computer games contributed to their understanding of climate change.

Climate change is a complex topic that involves complicated science and a knowledge of a wide range of science domains (Ekborg \& Areskoug, 2006), with many variables inter-relating over time, making precise predictions problematic. Therefore, long-term analysis and models are often used to help scientists, educators, and students describe, represent, or help make predictions about the phenomena. (Cartier, Rudolph, \& Stewart, 2001; Smith \& Stern, 2011). However, in order to depict the effects of climate change at the local level, models must represent the dramatic effects that are related to real effects at the local level (Pruneau, Liboiron, Vrain, Gravel, Bourque, \& Langis, 2001). For example, the gradual increase in temperature caused by climate change does not allow the average person to feel the effects on a daily basis, leading to confusion about climate change and the connection to average weather, global warming, and extreme weather events (Farmer \& Cook, 2013). As a result, many students have difficulty connecting climate change to their daily lives. Science teachers also struggle to overcome misinformation about the issue coming from media outlets, which reinforces misconceptions that persist among the population (Dawson \& Carson, 2013; Gayford, 2002). Also, topics related to GCC are taught in a disjointed way; for example, as a unit on the carbon cycle, another on weather and climate, and others on environmental effects. It is not surprising then, while the United States Climate Change Science Program (2009) suggests formal instruction is the best way for students to gain an understanding of the complex relationship between climate change and human impacts, students typically report learning about climate change through the Internet and television, resulting in further misconceptions and additional barriers for teachers to overcome when teaching this topic. (Liu, Roehrig, Bhattacharya, \& Varma, 2015).

Most science teachers do not explicitly include climate change in their curriculum and they are often under informed about climate change science. In addition, they hold similar misconceptions about climate change as their students, including the false conception that ozone depletion is a cause of global warming (Chi, 2005; Cordero, 2002; Herman, Feldman, \& Vernaza-Hernandez, 2015; Wise, 2010). However, it was found that teachers were more likely to teach climate change if they had support of local community members and school administration (Wise, 2010). Bunten and Dawson (2014) suggest many high school science teachers limit their instruction to wellunderstood and noncontroversial areas of science, thus misrepresenting science as a body of knowledge rather than a process of discovery.

In response to the issues discussed above, we developed and studied an innovative curriculum model to help high school students learn complex GCC science by connecting climate change and sea level rise to students' everyday lives, their recreational media interests, and local issues (Hallar, McCubbin, \& Wright, 2011). We developed the materials to be embedded into high school marine science, which is a popular science elective offered in high schools in our region. Climate Change Narrative Game Education (CHANGE) employs a web-based "intermedia" eBook narrative where sections of narrative text alternate with simulations/educational computer games. The narratives are about future southeastern United States residents (text stories with local characters, 50 to 100 years in the future based on GCC), use a local, place-based approach grounded in scientific data (Clark \& Mayer, 2008); and focus on the built environment. Our use of a future narrative set in the region where the curriculum materials are being used with a focus on the built environment serves to help students see themselves in the problem and time spaces of GCC, thereby reducing the abstract nature of global warming.

The incorporation of authentic scientific data is in line with the Next Generation Science Standards (NGSS Lead States, 2013) and with the curriculum standards for the marine science course. The simulations/educational computer games are based on scientific data to help students learn principles of GCC so students can experience and try to cope with potential long-term effects of GCC via role-play and science-based simulation. Because climate science is interdisciplinary in nature, the development of the narratives and simulations/games was a collaborative enterprise among people with expertise in educational technology, science education, climate science, educational measurement, and creative writing. In addition, four secondary science teachers were an integral and important part of the team by providing their expertise about teaching science in schools and by piloting the curriculum materials with their students.

In addition to the computer games contained in the eBook, the CHANGE project created other types of GCC curriculum materials to be embedded in the marine science course. However, as we noted above, this paper focuses 
on the use of the computer games. This paper is also limited to the teaching and learning of the effects of climate change on sea level and storms. This is because two of the major effects of climate change on coastal regions are (1) sea level rise and (2) larger and more frequent storms (IPCC, 2013). Climate change causes sea level rise in at least two ways: (1) as the water temperature rises, the volume increases, and (2) as overall temperatures rise, land-based glaciers melt, causes sea levels to rise even more (IPCC, 2013).

As anthropogenic climate change takes effect, the water temperature of oceans rise; for example, in the South Atlantic, which is the breeding ground of hurricanes. Water temperature directly fuels the intensity of hurricanes, and as a result, climate change will result in more severe storms. In addition, because of the increased heat energy in the oceans, there is a likelihood of more frequent major storms. Sea level rise also exacerbates the effects of storm surge, threatening low-lying coastal cities, and other low-lying inhabited coastal areas. As we have seen repeatedly, such as with Hurricane Katrina in New Orleans in 2005 and Hurricane Sandy in New York and New Jersey in 2012, storm surge, rather than winds, cause loss to human lives and significant damage to homes, businesses, and infrastructure. Therefore, these two effects, sea level rise and storms, combine synergistically to threaten low-lying coastal cities such as Miami, New York City, New Orleans, Houston, Hong Kong, and many others.

\section{Learning Model}

The CHANGE curriculum involves a variety of different materials. We have addressed some of the learning effects of parts of the CHANGE intervention (such as a local place-based approach, the use of the narratives, and the combination of all curriculum materials) in previous publications (Feldman et al., 2017; Smith et al., 2015; Smith \& Besalti, 2018). This paper focuses primarily on how a sample of the computer games affects the learning of climate change science.

For students, a great challenge to learning climate change is integrating the effects from various disciplines in ways that are understandable for them. The human visual system and its sibling, visual mental models, are potentially very effective for integrating and comprehending complex systems (Ainsworth, 2008). However, potential often does not become actual. Visualizing in science typically remains a challenge for many, if not most, students (Keim, Mansmann, Schneidewind, Thomas, \& Zeigler, 2008).

Educational computer games have great potential to help students integrate and visualize different multidisciplinary science effects, such as those in climate change science, for the following reasons:

1. Motivation: Because students perceive computer games as fun, they are willing to apply increased effort. The type of visual imagery needed to integrate multidisciplinary effects requires an effort of will (Hasher \& Zacks, 1979). Perhaps the fun of computer games can motivate students to exert this effort.

2. Core game mechanic: Computer games are designed around a core game mechanic (Schell, 2008), i.e., a repetitive cycle whereby the player (a) does some action to solve the problem or achieve the goal needed to win, (b) receives immediate real-time feedback on the effectiveness of the action, and (c) adapts his/her action on the basis of the real-time feedback to increase the likelihood of winning or achieving a subgoal. Because of the core game mechanic, during game-play students attempt to solve the problem again and again. This persistence is helpful for learning.

3. Isomorphism: This core mechanic in an educational computer game only helps students learn if the core game mechanic aligns with the educational goals. If the educational goal is helping students visualize complex scientific phenomenon, then the core game mechanic should be isomorphic (share the shape) with the scientific phenomenon. If the core game mechanic is isomorphic to the core educational content, then there is potential for kinesthetic and visual linkages that promote multi-modal memories, which can scaffold learning.

4. Adaptiveness: Many computer games, particularly recreational computer games, adapt to the competency of the player, maintaining an optimal challenge that is neither too easy, and thus boring, nor too difficult, and thus frustrating, but rather maintaining a level that is both challenging and fun for the player (Gee, 2005). This adaptive quality of some educational games has the potential to keep the student in the zone of proximal development (Vygotsky, 1987).

Clearly, if educational computer games are intended to promote visualization of complex climate change phenomenon, they should harness some of these qualities, including motivation, core game mechanic, isomorphism, and adaptiveness.

Another challenge in teaching climate change science is helping students rid themselves of misconceptions. Simulations are one teaching tool that can do so (Chen, Pan, Sung, \& Chang, 2013). When students learn from educational simulations they interact, trial and error fashion, with a computer model of some scientific phenomenon until ideally, their mental model of the phenomenon aligns with the computer model (De Jong \& Van Jooligen,1998). This is similar to what happens in educational games (Annetta, Cook, \& Schultz, 2007), which also 
contain abstracted models of reality. Students are immersed in the game, engage in metacognition, learn new content, and revise existing schemata. However, a simulation-based computer game adds other benefits (e.g., motivation and adaptiveness) beyond typical educational simulations to make the content more amenable to the student.

\section{Research Questions}

The current project was partly an attempt to test the notion that educational computer games provide an effective method to help students visualize complex climate change phenomenon and help students rid themselves of their misconceptions. In particular, we asked the following questions:

Research question 1 - What is the impact of the CHANGE intervention on

a) students' learning of climate change science, and

b) the validity of their beliefs about climate change?

Research question 2 - How do the educational computer games of the CHANGE curriculum contribute to understanding of two of the major effects of climate change on coastal regions: (1) sea level rise and (2) storms?

\section{METHOD}

\section{Site}

The site of the study is a large, county-wide school district in the southeastern United States that includes urban, suburban, and rural schools and populations. The CHANGE materials were delivered throughout the academic year in a marine science course. In 2016-2017, the course was taught in 26 high schools in the district by 27 teachers. The materials consist of 34 different activities including eBooks with embedded computer games, labs, and handson laboratory activities for nine marine science units. The teachers' usage of these materials varied. Throughout the 2016-2017 school year, some teachers completed as many as 28 of these 34 activities. Some of them only completed six or seven activities. Others did not report any use of them.

\section{Participants}

The participants were 511 students taking elective marine science courses, whose teachers reported using the CHANGE materials in their classes in the 2016-2017 academic year. To some extent, the teachers who adopted the CHANGE materials were also participants. Further, the students who took the marine sciences course, but whose teachers chose not to adopt the CHANGE materials, were indirect participants in a contrast group, since they also took the midterms and final exams, which included climate change questions. The study was approved by our university's Internal Review Board (IRB), as well as by an independent IRB.

\section{CHANGE Curriculum Materials}

In this paper, we report on our findings related to the use of computer games that were developed for two of the marine science units: marine chemistry and marine physics (see CHANGE website for the materials). The two games are the Glaciers versus Iceberg game in the marine chemistry unit, and the Hurricane Curling game in the marine physics unit. All of the games in this project, including the two games discussed extensively, were created by the researchers and authors of this paper.

One of the major causes of sea level rise is the melting of large slabs of ice in the Arctic and Antarctic, i.e. glaciers. However, a common misconception is that both the melting of icebergs and glaciers contribute to sea level rise. Glaciers are land-bound and when they melt, the runoff makes its way to the ocean, resulting in sea level rise. However, icebergs float in the ocean, so, according to Archimedes principle, they already are displacing their own volume in water. Therefore, when floating ice melts, it does not change the level of the water. This differentiation of the effects of glaciers versus icebergs on sea level rise is one of the themes we have addressed in the CHANGE materials and we have assessed, over two years, with several of the questions we have inserted into midterm and final exams. Because the exam data in our first two years of piloting the materials suggested that the students were not grasping the different effects of glaciers versus icebergs on sea level rise, we revised the materials to include more explicit instruction on that difference, and a game that targets the concept.

In the Glaciers versus Icebergs game (see Figure 1), the ability to differentiate the effects of melting glaciers versus icebergs is the key to winning the game. As a player, you are an archaeologist melting ice in search of the remains of woolly mammoths concealed in either landbound or waterbound ice in the vicinity of an Inuit village abutting a salt lake. If you melt too much land-based ice (glaciers), you raise the water level of the lake, flooding 


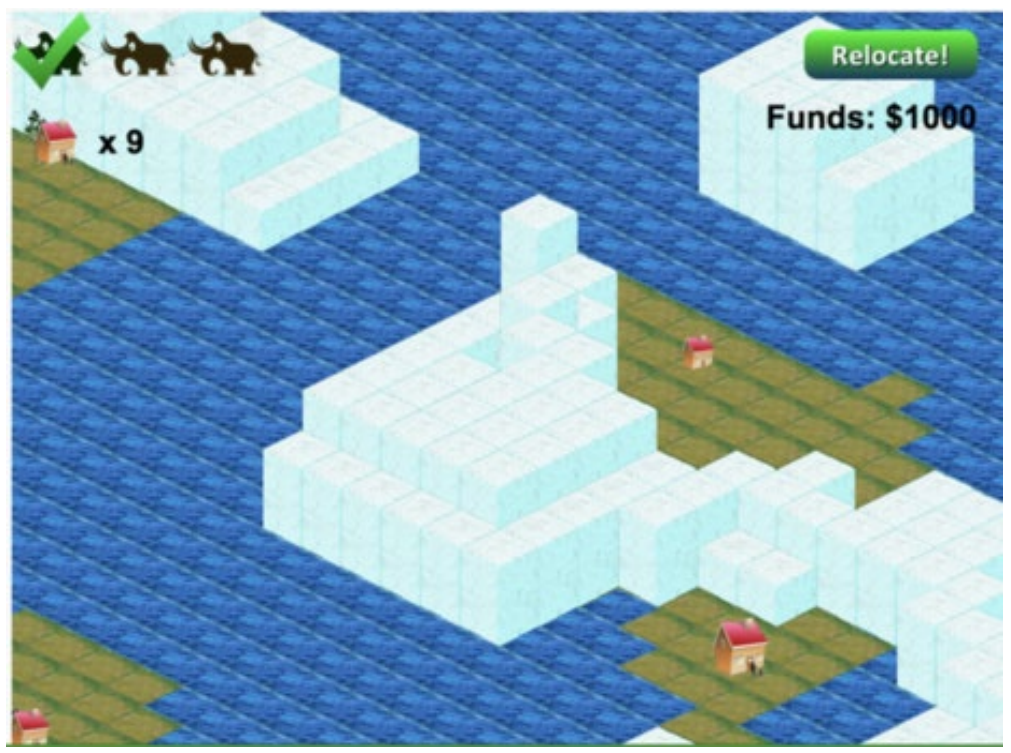

Figure 1. Screenshot from the Glaciers versus Icebergs game

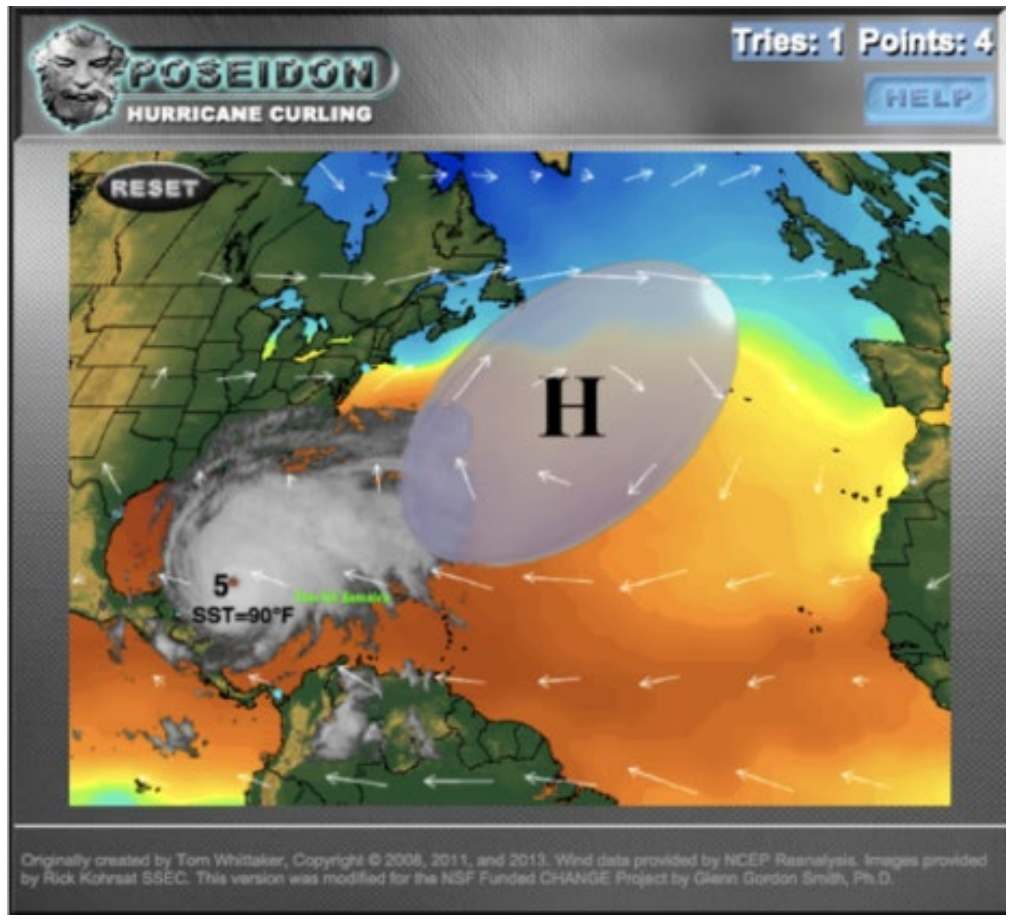

Figure 2. Screenshot of the Hurricane Curling game

some of the nearby houses. On the other hand, if you find woolly mammoths, you can earn money, which you can use to move the Inuit houses to higher ground. The idea is to provide a discovery-learning interactive game environment for students to learn the differential effects of melting glaciers versus icebergs on sea level rise.

The second game we focus on in this paper is the Hurricane Curling game (see Figure 2). This game is embedded in a chapter of the eBook in which the characters deal with the effects of a hurricane in their hometown. As in the sport of curling, players release a low-pressure system (analogous to the stone in curling) in the south Atlantic, and armed only with a "draggable" high pressure area (analogous to sweeping the ice with a broom) they try to get a category four or five hurricane to hit a local city on the gulf coast. The strength of the hurricane is influenced by the ocean temperature (as represented by the color of the pixels of the local area of the ocean in the image), while the direction of the hurricane is governed by the vectors of the prevailing winds and the players positioning of the high pressure area. To construct the game, we modified a hurricane simulation created by Tom Whittaker (2018) to provide game goals, scoring, and interaction, i.e., a core game mechanic. 


\section{Data Sources}

We used two sets of data to answer research question 1a: "What is the impact of the CHANGE intervention on students' learning of climate change science?" The first data set was the multiple-choice questions added to the districtwide marine science midterm and final exams. Fifteen questions related to GCC were added to the midterm, and fourteen to the final exam. These questions spanned the entire climate change curriculum.

The other data comes from the "End of Unit" (EOU) survey that was delivered to the students via SurveyMonkey. There were two types of question in the EOU survey: ones related to how the students learned using the CHANGE materials, and others that were content specific.

Our major data source for research question $1 \mathrm{~b}$, "What is the impact of the CHANGE intervention on the validity of students' beliefs about climate change?" was a pre- and post-online survey on students' beliefs about climate change (see Appendix A). The survey provided data about students' beliefs about the causes and implications of climate change through Likert-type questions. Specifically, the questions provided students with a set of statements for which they needed to indicate if they were true, probably true, probably false, or false. Their responses provided a measure of the validity of students' beliefs about climate change.

The survey was adapted from the CACCE teachers survey (Herman et al., 2015), the Yale Six America's survey (Leiserowitz, Maibach, Roser-Renouf, \& Smith, 2011), and the Bostrom (1994) survey of educated lay people and their understanding of climate change. It was created in June 2015 and initially piloted in August 2015. The survey is comprised of 21 questions, including open-ended, rank-ordered, Likert-type questions, and an additional twelve content questions. The instrument was used to identify and categorize understandings of climate change and beliefs about the causes and implications of climate change. Respondents also reported their level of concern about how the impact of climate change would affect them personally, and personal actions they believe would help mitigate the impacts of climate change.

In order to answer research question 2, "How do the educational computer games of the CHANGE curriculum contribute to understanding two of the major effects of climate change on the coastal regions: (1) sea level rise and (2) storms?" we used the EOU surveys that contained open-ended questions related to the games. For the marine physics unit, we asked the question "Do you feel that the computer game (Hurricane Curling game) helped you learn climate change science? If yes, why? If no, why not?" Similarly, at the end of the marine chemistry unit, we asked students, "Do you feel that the computer game (Glacier versus Iceberg game) helped you learn climate change science? If yes, why? If no, why not?"

\section{DATA ANALYSIS}

Quantitative data gathered from the student's belief survey, midterm, and final exam results were analyzed using SPSS (Statistical Package for the Social Sciences). For the student belief survey analysis, an ANOVA test was used to compare the means from the initial data with the end of year data. Results from the midterm and final exam were analyzed using an ANOVA test to examine the difference of scores between students who experienced the CHANGE curriculum and the students who did not in order to determine the impact of the CHANGE curriculum on students' understanding of climate change science.

Qualitative data gathered from online end of unit surveys were analyzed using a computer-assisted data analysis software called HyperRESEARCH. The online end of unit surveys were coded using an inductive coding process (Miles, Huberman, \& Saldana, 2014) to determine how the computer games affected students' learning of climate change science, specifically related to storms and sea level rise. Students' survey responses were coded using both open and axial coding to attempt to generate theory based on the data (Grbich, 2013). Codes were first created by reading through survey responses and applying descriptive labels to words and phrases (Miles et al., 2014). Then, common themes were developed through axial coding within and across the students' responses (Grbich, 2013). After similar codes were grouped together by themes, frequency distributions were generated for the codes. Finally, the themes were used to generate a theoretical model (Grbich, 2013) to explain how computer games impacted students' learning of climate science. Member checking occurred between graduate students and (Principal Investigators) PI's to improve the quality of the findings and conclusions throughout the data analysis.

\section{RESULTS}

\section{Quantitative Analysis}

To address research question 1 a of this paper, “What is the impact of the CHANGE intervention on students' learning of climate change science?" we used the data from the questions related to climate change that we inserted into the 
midterm and final exams. The final exam was not cumulative, it only tested the material covered during the second semester of the course.

We conducted two different analyses to determine how CHANGE curriculum materials affected students' achievement on these exams. In our first analysis, we created four groups based upon the teachers' usage of the CHANGE materials in the classroom. We periodically sent emails to the teachers asking them to report which CHANGE materials they used in their curriculum. Based upon their responses, we created the four groups (coded as $0,1,2,3)$; with 0 being teachers who did not report the use of our materials at all. Group 3 mostly used our materials, group 2 had moderate usage of the materials, and group 1 used our materials, but considerably less. Although the teachers in group 0 did not report the use of CHANGE materials, they may have taught climate change in other ways. We then calculated students' raw scores on the questions, in both midterm and final exams. After grouping students and calculating their raw scores, we conducted a one-way between-subjects ANOVA to compare the performance of students for the most usage, moderate usage, less usage, and no usage of the CHANGE materials.

On the midterm exam for the marine science course, we included fifteen additional questions related to climate change science. For the honors students, who were more numerous than the "regular" (non-honors students) in the course, there were significant differences in their percentage scores on the exam questions at the $p<.05$ level, for the four conditions based on CHANGE material usage $[F(3,1352)=11.491, p=0.000]$. Post hoc comparisons using the (Least significant Difference) LSD test indicated that the mean scores for the most usage condition $(M=53.0$, $S D=17.02)$, moderate usage condition $(M=51.7, S D=17.66)$, and less usage condition $(M=52.8, S D=19.18)$ were significantly higher than for the no usage condition $(M=46.31, S D=16.56)$. Partial eta squared was .025 , for a medium effect size. However, there were no statistically significant differences between the three groups (the most, moderate, and less usage conditions).

For the regular students (non-honors), there were only three groups (moderate, less, and no usage of the materials). The analysis showed that there was also a significant difference between their percentage score on the exam questions, at the $p<.05$ level, for the three conditions based on the level of CHANGE material usage [ $F(2$, $451)=35.555, p=0.000]$. Post hoc comparisons using the LSD test indicated that the mean scores for the moderate usage condition $(M=51.6, S D=20.67)$ and less usage condition $(M=43.3, S D=15.99)$ were significantly higher than for the no usage condition $(M=34.3, S D=14.62)$. Additionally, students who used the CHANGE materials moderately scored better than those who used the materials less.

The final exam included fourteen additional questions related to climate change science. For the honors students in the course, there were significant differences in their exam percentage scores on the climate change questions, at the $p<.05$ level, for the four conditions based on CHANGE materials usage $[F(3,857)=6.663, p=0.000]$. Post hoc comparisons using the LSD test showed that the mean score for the most usage condition $(M=46.34, S D=13.47)$ was significantly different than the no usage condition $(M=41.73, S D=15.17)$. However, there were no statistically significant differences between moderate usage versus no usage, or less usage versus no usage.

As with the midterm, the regular students comprised only three CHANGE materials usage groups (moderate, less, and no usage of the materials) on the final exam. The analysis indicated that CHANGE materials usage level exerted a significant effect, at the $p<.05$ level, on regular students' percentages on climate change-related exam questions, $[F(2,270)=7,700, p=0.001]$. Based upon post hoc comparisons using the LSD test, the mean scores for the moderate usage condition $(M=43.80, S D=12.82)$ was significantly different than the no usage condition $(M=$ $36.12, S D=14.04)$. However, there was no significant difference between less usage group and no usage group in the final exam.

In our second analysis, we compared two groups (students who used the CHANGE materials versus those who did not). On the midterm exam, for the honors students, there was a significant difference in percentage score, on questions we created, between those who used the CHANGE materials $(M=52.73, S D=17.98)$ versus those who $\operatorname{did} \operatorname{not}(M=46.31, S D=16.56), F(1,1354)=33.88, p<.000$, partial eta squared $=0.024$ (small effect size). For the regular students, there was also a significant difference between those who used the CHANGE materials $(M=$ $46.02, S D=18.0)$ versus those who did $\operatorname{not}(M=34.39, S D=14.62), F(1,452)=56.28, p<.000$, partial eta squared $=$ 0.111 (large effect size).

The results were similar on the final exam. For the honors students, there was a significant difference in percentage correct between those who used the CHANGE materials $(M=44.5, S D=15.1)$ versus those who did not $(M=41.7, \mathrm{SD}=15.1), F(1,860)=5.93, p<.015$, partial eta squared $=0.007$ (small effect size). For those students who were not honors students, there was also a significant difference in percentage correct between those who used the CHANGE materials $(M=43.2, S D=15.8)$ versus those who did $\operatorname{not}(M=36.1, S D=14.0), F(1,272)=15.4, p<.0001$, partial eta squared $=0.054$ (medium effect size).

To address research question $1 \mathrm{~b}$ of this paper, "What is the impact of the CHANGE intervention on students' beliefs about climate change?" we used the data from the students' beliefs survey (see Appendix A) administered before and 
Table 1. Positive exemplars of codes used for analysis of Hurricane Curling game open-ended question from the EOU survey

\begin{tabular}{|c|c|c|}
\hline Positive Codes & Exemplar & $\mathbf{N}$ \\
\hline Visualization & $\begin{array}{l}\text { The game where you had to move the hurricane to Florida helped a lot because it showed how } \\
\text { the storms travel and how they can quickly gain and lose power. } \rightarrow\end{array}$ & 86 \\
\hline Fun & It's a more fun and exciting way to learn more. & 77 \\
\hline $\begin{array}{l}\text { Helped me learn the } \\
\text { facts about hurricane }\end{array}$ & $\begin{array}{l}\text { The game about the factors that influence a storm like the pressure, winds and water } \\
\text { temperature helped me learn a lot about those factors. }\end{array}$ & 51 \\
\hline Engaging $\rightarrow$ & $\begin{array}{l}\text { It was engaging and helped me understand how hurricanes move, including the difference in } \\
\text { movement over land and water, and how pressure and winds influence its path. }\end{array}$ & 43 \\
\hline Helped me learn/general & I learned that climate change affects a lot more than I thought. & 26 \\
\hline Interactive & Due to the interactivity of it, it was very helpful on my education of the topic. & 21 \\
\hline Positive/no reason given & Amazing! & 19 \\
\hline $\begin{array}{l}\text { Active learning/doing } \\
\text { something }\end{array}$ & $\begin{array}{l}\text { It helped me with practicing what areas to move the hurricane to and what climate can cause } \\
\text { hurricanes easily. }\end{array}$ & 17 \\
\hline Hands on learning & It gives a chance to be more hands-on instead of just reading passages. & 14 \\
\hline Related to real life & I like computer games so it helped by letting me relate it to my real life. & 6 \\
\hline Helped memorization & It helped me memorize it easier. & 5 \\
\hline Interesting & It made it more interesting. & 4 \\
\hline Provided details & It provides reasonable explanations rather than text book definitions. & 4 \\
\hline
\end{tabular}

Table 2. Themes about the Hurricane Curling game

\begin{tabular}{lll}
\hline Themes & Exemplar & $\mathbf{N}$ \\
\hline Affective & Fun, engaging, interesting; no statements of what was learned or how it was learned \\
\hline Learned facts & Defines facts/concepts/etc. about hurricanes; what was learned, not how \\
\hline Visualization & Learns about formation, etc. of hurricanes due to visual qualities of games $\rightarrow$ \\
\hline Interactive & Learns hurricane because of ability to interact with game & 143 \\
\hline
\end{tabular}

Total: 373

after the intervention. The students' beliefs were measured by twenty Likert-scale questions, i.e., whether they thought a series of climate-centered statements were true, probably true, probably false, or false. To compute a cumulative raw score, we did the following: If the statement was true and they selected true, they received two points. If they selected probably true to a true statement, they received one point. False or probably false, received zero points. Similarly, If the statement was false and they selected false, they received two points. If they selected probably false to a false statement, they received one point. For true or probably true, they received zero points.

Based upon the pre- and post- test scores, there was a significant increase in their raw score, between pre-test $(\mathrm{M}=18.23, \mathrm{SD}=4.47)$ versus post-test $(\mathrm{M}=19.58, \mathrm{SD}=4.95), F(1,510)=10.36, p<.001$, partial eta squared $=0.28$ (small effect size).

\section{Qualitative Analysis}

We used the open-ended questions from the EOU surveys to answer research question 2: How do the educational computer games of the CHANGE curriculum contribute to understanding two of the major effects of climate change on coastal regions: (1) sea level rise and (2) storms?

For storms, we analyzed responses to an open-ended question in which we asked the students, "Do you feel that the computer game (Hurricane Curling game) helped you learn climate change science? If yes, why? If no, why not?" The students' responses were overwhelmingly positive about the game. Of the positive responses about the computer game, we coded 373 responses in which students stated that the computer game helped them to visualize how hurricanes are formed and move $(n=86)$, to learn the facts about hurricanes $(n=51)$ or to learn generally $(n=26)$. They also found that the game was fun $(n=77)$, engaging $(n=43)$, or interactive $(n=21)$. Some students stated that the game allowed them to be actively involved in the learning environment $(n=17)$ and it was hands-on learning for them $(n=14)$. Exemplars for the positive codes can be found in Table 1. Note that the codes below are not mutually exclusive, i.e., one student response could receive multiple codes.

We found that some of the codes above were related thematically, such as Interactive, Active learning/doing something, and Hands on learning. Therefore, we grouped the codes into four themes (see Table 2).

We also had some negative responses about the game. Some students found the game to not be engaging or fun $(n=33)$, confusing $(n=25)$, or hard to play $(n=20)$. Some also stated that the game did not help them to learn (without providing any reason why) $(n=16)$ or did not like it $(n=14)$. Exemplars for the negative codes can be found in Table 3. 
Table 3. Negative exemplars of codes used for analysis of Hurricane Curling game open-ended question from the EOU survey

\begin{tabular}{llc}
\hline Negative Codes & Exemplar & N \\
\hline Not engaging or fun & It was not engaging or interesting. & 33 \\
\hline Confusing & No, it was confusing and did not explain the game well enough. & 25 \\
\hline Hard to play & It was really hard to understand and I kept trying to get it but I couldn't. $\rightarrow$ & 20 \\
\hline No reason given & The game didn't help me at all. & 16 \\
\hline Did not like it & I didn't like the computer games as much because I felt like it was a little kid game. & 14 \\
\hline Lack of directions & It didn't help because I wasn't sure what to do. & 12 \\
\hline Time consuming & The computer game was hard to pass and time consuming. & 7 \\
\hline
\end{tabular}

Total: 127

Table 4. Positive exemplars of codes used for analysis of Glaciers versus Icebergs game open-ended question from the EOU survey

\begin{tabular}{llc}
\hline \multicolumn{1}{c}{ Positive Codes } & \multicolumn{1}{c}{ Exemplar } & N \\
\hline Fun & The game was fun and it helped me grasp the concept better. & 70 \\
\hline Helped me learn/general & $\begin{array}{l}\text { I really liked the computer game because it allowed me to understand the subject } \\
\text { better by playing them. }\end{array}$ & 61 \\
\hline Engaging $\rightarrow$ & $\begin{array}{l}\text { The activities keep me more engaged and opens my understanding more of what's } \\
\text { actually going on in the lesson. }\end{array}$ & 42 \\
\hline Visualization & $\begin{array}{l}\text { It showed how climate change can cause glaciers to melt and cause sea level rise } \\
\text { Which as a result flooded the houses. }\end{array}$ & 39 \\
\hline $\begin{array}{l}\text { Helped me learn the facts about } \\
\text { sea level rise }\end{array}$ & $\begin{array}{l}\text { It taught me that as glaciers melt, it displaces the water causing flooding which } \\
\text { destroys land and wildlife. }\end{array}$ & 23 \\
\hline Interactive & $\begin{array}{l}\text { The computer game gave me a way to interact with the Information and interpret it } \\
\text { in a more efficient way. }\end{array}$ & 23 \\
\hline Positive/no reason given & Yes, everything! & 17 \\
\hline Hands on learning & $\begin{array}{l}\text { The computer game helped me learn climate change science because it was hands } \\
\text { on. }\end{array}$ & 11 \\
\hline Interesting & $\begin{array}{l}\text { It was interesting because I learned about how glaciers work and how they can } \\
\text { affect animals and housing. }\end{array}$ & 9 \\
\hline Related to real life & Yes. The real life situation gave me a perspective on how climate can change. & 6 \\
\hline $\begin{array}{l}\text { Active learning/doing } \\
\text { something }\end{array}$ & $\begin{array}{l}\text { Me being the "scientist" having to be careful where and what glacier I would have to } 3 \\
\text { be allowed to carve in or it would cause flooding to house because it's making } \\
\text { oceans rise. }\end{array}$ \\
\hline Provided details & Giving details and how it will affect us. & \\
\hline Total:306 & & \\
\hline
\end{tabular}

Table 5. Themes about the Glacier versus Iceberg game

\begin{tabular}{llc}
\hline Themes & Exemplars & $\mathbf{N}$ \\
\hline Affective & $\begin{array}{l}\text { Fun, engaging, interesting; no statements of what was learned or how it was } \\
\text { learned }\end{array}$ & 138 \\
\hline Learned facts & Defines facts/concepts/etc. about sea level rise; what was learned, not how & 92 \\
\hline Visualization & Learns about sea level rise due to visual qualities of games & 39 \\
\hline Interactive & Learns sea level rise because of ability to interact with game & 37 \\
\hline \hline
\end{tabular}

Total: 306

For the Glaciers versus Icebergs game we asked the students, "Do you feel that the computer game (Glaciers versus Icebergs game) helped you learn climate change science? If yes, why? If no, why not?" Similar to the Hurricane Curling game, the students' responses were mostly positive. Of the positive responses, we coded 306 responses in which students stated that the computer game was fun $(n=70)$, engaging $(n=42)$, and helped them to visualize how climate change can cause glaciers to melt and cause sea level rise $(n=39)$. They also found that the game helped them to learn general knowledge about sea level rise $(n=61)$ and specific facts how it occurs $(n=23)$. In addition, some students stated that the game was interactive $(n=23)$ and it was hands-on learning for them $(n=11)$. Exemplars for the positive codes can be found in Table 4.

As for the Hurricane Curling game, we combined these codes into four themes (see Table 5).

Of the negative responses about the Glacier versus Iceberg game, we coded 146 responses in which students stated that the computer game was not engaging or fun $(n=60)$, was confusing $(n=46)$, and that there was a lack of directions in the game $(n=10)$. We also had some students $(n=4)$ who, after playing the game, still had 
Table 6. Negative exemplars of codes used for analysis of Chemistry open-ended question from the EOU survey

\begin{tabular}{llc}
\hline Negative Codes & Exemplar & $\mathbf{N}$ \\
\hline Not engaging or fun & $\begin{array}{l}\text { The computer games are my biggest issue with this, as sometimes they are fine but never } \\
\text { engaging, fun or a learning experience. }\end{array}$ & 60 \\
\hline Confusing & $\begin{array}{l}\text { I thought the computer game only showed us that ice caps melt, which I already have a good } \\
\text { understanding of, but finding the mammoths and saving the houses was a confusing aspect } \\
\text { that I feel didn't relate to the chemistry of our oceans. }\end{array}$ & 46 \\
\hline Lack of directions & $\begin{array}{l}\text { I didn't see the purpose in playing the game. I don't understand how it taught us about } \\
\text { climate change. I didn't like how there were no instructions and or objective to the game. }\end{array}$ & 10 \\
\hline Time consuming & The game consisted of aimlessly clicking ice cubes, seemed like a waste of time. & 9 \\
\hline Did not like it & It wasn't a good example for marine chemistry. & 7 \\
\hline No reason given & Did not help. & 7 \\
\hline Misconception & It helped me learn about the melting of sea ice and how it can flood houses. & 4 \\
\hline Hard to play & $\begin{array}{l}\text { It was difficult and did not explain what was going on? And because it was so difficult I did } \\
\text { not feel I learned anything. }\end{array}$ & 3 \\
\hline
\end{tabular}

Total: 146

misconceptions about which (glaciers or icebergs) cause sea level rise. These students thought that melting icebergs (seabound ice masses) also cause sea level rise. Exemplars for the negative codes can be found in Table 6.

\section{DISCUSSION}

Research question 1A was "What is the impact of the CHANGE intervention on students' learning of climate change science?" We answered this question by inserting questions about climate change science into the midterm and final exams of a high school marine science course. We conducted separate analyses for honors and regular students. We also grouped the classes who used the CHANGE materials according to usage (in three or four groups). The general pattern was that the students, whether honors or regular, scored significantly higher on the exams in the full usage group, than in the no usage group, however students with moderate or minimal usage of CHANGE materials did not score significantly higher than no usage. There was one exception. On the midterm, honors students with moderate usage also scored higher than those with no usage. These results suggest that the CHANGE intervention did result in significantly more learning of climate change science. However, full usage of materials was important. Fidelity of implementation was a factor.

We used a twenty question, pre- and post-survey to address research question $1 \mathrm{~b}$ of this paper "What is the impact of the CHANGE intervention on the validity of students' beliefs about climate change?" Based on this instrument, the students made a modest gain (small effect size) in valid beliefs about climate change. This does suggest the value of the CHANGE intervention in terms of change of beliefs about climate change. On the other hand, it also points out the complexity of climate change, which involves integrating scientific concepts from a variety of disciplines, and projecting these concepts to a wide variety of emergent effects. These effects often involve probabilities, and probabilities of projected ranges of effects. Because of this wide variety of effects, it is difficult to accurately measure change in beliefs. Therefore, it is somewhat remarkable that this modest survey of 20 questions produced significant before and after change.

We addressed research question 2 "How do the educational computer games of the CHANGE curriculum contribute to understanding two of the major effects of climate change on the coastal regions: (1) sea level rise and (2) storms?" by means of open-ended questions delivered to the students after completing the unit. For the Hurricane Curling game, there were 373 positive comments from the open-ended survey and 127 negative, which is a ratio of 2.94 . In other words, positive comments outnumbered negative comments almost 3 to 1 . This overwhelmingly positive perception of this game is remarkable when you consider that this game was created by team of a professor and two students on a rather low budget. One might think that high school students who are no doubt used to the high production values of commercial computer games (which typically have production budgets in the millions) would look askance at educational computer games created by a university team, which must have lower productional values. However, we hypothesize two effects at play: (1) Students encountering educational computer games in the context of a high school course are not necessarily comparing to them to commercial games, which they encounter in their recreational sphere. They are comparing them to activities they would be doing otherwise in the class. (2) The proliferation of "casual" two-dimensional (2D) computer games in the last ten years, played on smartphones and other handheld devices, provides a much less harsh comparison than commercial 3D games.

Of the students who did make negative comments, some thought it wasn't fun, or that it was childish. Others couldn't figure out how to play the game, which was puzzling since there were directions. 
The open-ended survey question "Do you feel that the computer game (Hurricane Curling game) helped you learn climate change science? If yes, why? If no, why not?" produced these broad categories of responses in the order from more to less frequent: (1) affective, (2) learned facts, (3) visualization, and (4) interactions (see Table 2). One may view these categories as progressively taking more advantage of the unique learning affordances of educational computer games, in close to the same order: (1) learned facts, (2) affective, (3) visualization, and (4) interactions. Learned facts, the lowest level of Bloom's Taxonomy of learning outcomes (Bloom, 1956), are often the preliminary phase in a course of learning, the necessary, but not sufficient condition, for learning higher levels of Bloom's Taxonomy. The learning of facts is not necessarily the best use of educational computer games, as will be seen in the discussion below.

One hallmark of computer games is their motivational appeal, or their ability to engage players emotionally (Gee, 2005; Prensky, 2003). Affective was, by a large margin, the most frequent of the collapsed categories. Positive affect indirectly promotes learning. As the principle of "conation" (Hilgard, 1980) makes clear, students will only learn if they are motivated to learn. Therefore, any extra motivation engendered by use of an educational computer game is useful.

Another hallmark of computer games is the "game mechanic" (Schell, 2008), the repeated cycle of interaction, with feedback, as the player makes attempts to complete the task that will win the game. The game mechanic typically plays out in an interactive graphic setting, i.e., graphics that animate and respond to interactions from the player. Thus, educational computer games lend themselves to visual and progressive outcomes, such as models of processes that can be seen and interacted on, specifically the visualization of complex scientific phenomena.

Further, players must first learn the "rules" of a game, whether they be explicit or implicit and how to play the game, before they can learn from a game. Thus, it the logical deduction of the current authors that an educational computer game has its own extraneous cognitive load built into its learning experience. To justify this additional extraneous cognitive load, the learning outcome should be something that is hard for students to learn in other ways. Thus, the most apropos learning outcomes for educational computer games are typically visual and process oriented and higher up on Bloom's Taxonomy. Also, given, the large time and financial investment, and skills necessary to create an educational game, it makes sense to select core learning content that is hard to get students to learn with conventional techniques.

When we, as educators using or designing educational computer games, see this list of broad categories of responses: (1) learned facts, (2) affective, (3) visualization, and (4) interactions, it may suggest a progression from less to more appropriate outcomes for an educational computer game. "Learned facts" may be handled more efficiently by other curriculum methods besides games, because (a) games require the extraneous cognitive load (Sweller, 1994) of learning the game and any game play not directly relating to the content and (b) the development of an educational game is laborious, expensive and requires considerable skill contributors.

Positive affective responses may exert motivational leverage to learn a topic. Given the potentially outsize motivational qualities of computer games, the game might make a topic more attractive to students who would otherwise be averse to the content. Playing an educational game related to content can boost engagement with the content (Garris, Ahlers, \& Driskell, 2002). However, given the potential of educational computer games to address learning outcomes not easily attainable by conventional means, affective responses alone only marginally justify the difficulty in creating games, and the extraneous cognitive load that games exert on the content.

Visualizing scientific phenomenon is valuable for student learning of science (Ainsworth, 2008), however it is often challenging (Keim et al., 2008). Educational computer games are well-suited for visualization if they are designed so that winning the game calls attention to, and requires interaction with, a model of the content to be visualized (Li \& Tsai, 2013; Boller \& Kapp, 2017). It is also worth noting that visualization operates with two representations: (1) external representations, such as computer graphics, diagrams in books, etc., and (2) internal human representations, in human cognitive systems, which involve both automated visual processing and the systems requiring an effort of will and attention (Ainsworth, 2008; Kosslyn, 2005; Kosslyn, Ball, \& Reiser, 1978). For visualization to be effective, it needs to work at both levels, external and internal human representations.

However, visualization is not the exclusive province of computer games. There is much software for scientific visualization that is not game-like. One, of a number of things, that makes educational computer games different from scientific visualization software is the game mechanic, i.e., having win and lose conditions and a repetitive cycle of interactive attempts to win, coupled with immediate feedback on the effectiveness of those attempts, such that the player can adapt their behavior.

It is the interaction in the game mechanic that facilitates the adaptation of player behavior (Gee, 2005). If the game mechanic is isomorphic to the core educational content, then adaptation of player behavior should result in a parallel adaptation of learning understanding (Boller \& Kapp, 2017). Thus, it is dear to the heart of a designer of educational computer games to hear students describe the learning value of the computer game as helping to visualize phenomenon by interacting with the game mechanic. 
Based on the answers to the open-ended questions, the Hurricane Curling Game provided an unexpected learning bonus. The game contributed a different kind of understanding, above and beyond factual knowledge, that you would not likely obtain from more conventional educational materials. Many of the students' answers (e.g., "The different aspects of the storm that you could change showed how those aspects influence a hurricane" and "It gave me a good interactive visual representation of the path a hurricane takes and why it takes that path.") reflected that they learned how a hurricane develops and moves. This was due to students performing repeated cycles of interaction and feedback in the game (what is known as the "game mechanic" in game design circles).

The game mechanic in the Hurricane Curling Game was releasing a low-pressure area, somewhere off the coast of Africa in an attempt to strike Tampa with a category 4 or 5 hurricane, guiding it with high pressure and obtaining feedback. We hypothesize that what really helped students learn how hurricanes develop and move was that this game mechanic was set in a somewhat realistic simulation model of hurricanes. The model was based on a digital map of the Atlantic, complete with vectors representing prevailing winds and the colors of pixels representing water temperature. The prevailing winds, along with interaction with high pressure areas (which players can control) and other low-pressure areas, determines where hurricanes move. The water temperature (represented by the color of the pixels) determines the power of the hurricane.

\section{Iceberg versus Glacier Game}

The answers to the open-ended question "Do you feel that the computer game (Iceberg versus Glacier Game) helped you learn climate change science? If yes, why? If no, why not?" shed light on the effectiveness of game.

The number of positive responses to the game was 306 and the number of negative responses was 149. Although the ratio of positive to negative was 2.1 for this game, which appears to be considerably less than that for the Hurricane Curling game (3.0), it was still overwhelmingly positive. Why the Iceberg versus Glacier game was regarded less positively than the Hurricane Curling game is an interesting question. Both games were built on top of a simulation, but the hurricane simulation was much more realistic and sophisticated. Because of that, students perhaps felt they learned more.

The goal of the Glacier versus Iceberg game was to have students learn, or at least reinforce learning, that melting glaciers (landbound ice masses) raise sea level, while melting icebergs (seabound ice masses) do not. Of the student responses that explicitly addressed the differential effect glaciers versus icebergs have on sea level, 23 got it right (melting glaciers raise sea level; melting icebergs do not), while 4 did not. This forms a ratio of 5.75. The open-ended question did not explicitly ask about sea level rise, so the vast majority of students did not mention it in their responses. However, the 27 students who did mention sea level rise in their answers are likely representative of the other students. Thus, the 27 students can be considered a sample. This suggests that the game was effective in advancing its goal. One might consider learning that melting glaciers raise sea level while melting icebergs do not is merely learning a fact, and thus not an appropriate use of an educational computer game. However, the history of the CHANGE project suggests that repeatedly mentioning this as a fact to students does not make this stick. However, providing this information in an interactive visualization in game form apparently did.

The Glacier versus Iceberg game had the same broad categories of responses, in the same order from more to less frequent: (1) affective, (2) learned facts, (3) visualization, and (4) interactions. Although, both games were quite different, the qualitative reaction to the games was remarkably similar. On the one hand, this may not be a total surprise. The overall context in which the games were played (the CHANGE intervention in marine sciences classes) was quite similar. Both of these games were simulation games. However, how these games were designed was dramatically different. The Hurricane Curling game originated as a simulation that was modified to include more game-like features, such as win-lose conditions, scoring, and a storyline. Based on its origin as a simulation, the Hurricane Curling game's model of the phenomenon was multidimensional (including prevailing winds, high and low-pressure areas, water temperatures, and how the interaction of all of these elements influences both the path and strength of hurricanes). Further, the model had a fairly high resolution, at least in the case of modeling the influence of water temperature on the strength of hurricanes. The percentage of red in the individual pixels in the background image of the Atlantic Ocean, directly underneath the animated gif representing the hurricane, was used as a measure of water temperature, which in turn influenced the change in strength of the hurricane. Given that the resolution of the background image of the Atlantic Ocean was 72 pixels per inch (or 5,184 pixels per square inch), this is a relatively high resolution for the underlying model. The Glaciers versus Iceberg game also had an underlying model. However, since the game was entirely created from scratch by the researchers, the model had fewer dimensions (icebergs, glaciers, and how the melting of the ice differentially affected water level). Moreover, the resolution of the model was considerably coarser. The model was based on cubes, within an isometric perspective, with a resolution of approximately 27 cubes per square inch. One might infer, at least in this case, that how students perceive a simulation game is not strongly influenced by the dimensionality or the resolution of the underlying model. 


\section{CONCLUSION}

Anthropogenic climate change is certainly one of the most urgent issues facing the world at this time. Addressing it requires a knowledgeable and vigorous response by citizens. Today's students are tomorrow's leaders. Yet, climate change education faces some daunting obstacles: its causes and effects cross disciplines, while science education remains largely "siloed." Nature, in its wild recklessness, ignores disciplinary boundaries.

The results of the current study strongly suggest a model for climate change science education. First of all, climate change science can be taught at the high school level in an interdisciplinary way, using a local place-based approach, and including media that specifically appeals to the current generation of high school students (educational computer games). Such an approach can result both in significant learning about climate change science, as well as significant improvement in beliefs about climate change.

This paper provides a case study on how educational computer games can fit meaningfully into climate change education. The authors opinion is that the results demonstrate that simulation-style computer games, in addition to engaging students in climate change topics, can also help them visualize complex scientific phenomenon. Student interaction with the underlying model of the phenomenon in the game can scaffold this student visualization process. The motivational aspects of the games help students persist with the interaction and learning. The authors encourage other educators to both to use such games in the classroom, but also to consider developing such games themselves (as the investigators here).

Finally, the current authors invite science educators around the world to: (1) use our materials if they see fit. We can make these materials available for their own educational use, if they inquire about it; and (2) use what we have done as a model for developing comparable climate change science interventions. Our local place-based approach can be reproduced for other locations. The effects of climate change are global and will, and already have had, local effects around the globe. A place-based approach provides the means to make anthropogenic climate change science feel much more relevant to high school students. Further, the use of educational media, such as computer games, which relate to high school students' recreational activities, provides a means to motivate students to learn the climate change science content. Educational computer games also potentially provide learning affordances, different from other more traditional education approaches. As revealed in the data in the current paper, educational computer games can provide a highly accessible interactive visualization for complex scientific phenomenon.

\section{ACKNOWLEDGEMENTS}

The authors thank the National Science Foundation for their support in the form of a grant, NSF DRK12 1316782.

\section{REFERENCES}

Ainsworth, S. (2008). The educational value of multiple-representations when learning complex scientific concepts. In Visualization: Theory and practice in science education, Edited by: Gilbert, J. K., Reiner, M. and Nakhleh, M. 191-208. Dordrecht, The Netherlands: Springer. https:// doi.org/10.18608/jla.2017.42.16

Annetta, L. A., Cook, M., \& Schultz, M. (2007). Video Games: A Vehicle for Problem-Based Learning. e-Journal of Instructional Science and Technology, 10(1).

Bentley, M. L., Ebert, E. S., \& Ebert, C. (2007) Teaching Constructivist Science: Nurturing Natural Investigations in the Standards-Based Classroom. Thousand Oaks, CA: Corwin Press.

Bloom, B. S. (1956). Taxonomy of educational objectives. Vol. 1: Cognitive domain. New York, NY: McKay.

Boller, S., \& Kapp, K. (2017). Play to Learn: Everything You Need to Know About Designing Effective Learning Games. Alexandria, VA: Association for Talent Development.

Bunten, R., \& Dawson, V. (2014). Teaching climate change science in senior secondary school: Issues, barriers and opportunities. Teaching science, 60(1), 10-18.

Cartier, J., Rudolph, J., \& Stewart, J. (2001). The nature and structure of scientific models. National Center for Improving Student Learning and Achievement in Mathematics and Science.

Chen, Y., Pan, P., Sung, Y., \& Chang, K. (2013). Correcting Misconceptions on Electronics: Effects of a simulationbased learning environment backed by a conceptual change model, Journal of Educational Technology $\mathcal{E}$ Society, 16(2), 212-227.

Chi, M. (2005). Commonsense conceptions of emergent processes: Why some misconceptions are robust. Journal of the Learning Sciences, 14(2), 161-199. https:/ / doi.org/10.1207/s15327809jls1402_1

Clark, R. C., \& Mayer, R. E. (2008). Learning by viewing versus learning by doing: Evidence-based guidelines for principled learning environments. Performance Improvement, 47(9), 5-13. https:/ / doi.org/10.1002/ pfi.20028 
Cordero, E. C. (2002). Is the ozone hole over your classroom?. Australian Science Teachers Journal, 48(1), 34-39.

Dawson, V., \& Carson, K. (2013). Australian secondary school students' understanding of climate change. Teaching Science, 59(3), 9-14.

De Jong, T., \& Van Joolingen, W. R. (1998). Scientific discovery learning with computer simulations of conceptual domains. Review of Educational Research, 68(2), 179-201. https://doi.org/10.1002/pfi.20028

Ekborg, M., \& Areskoug, M. (2006). How student teachers' understanding of the greenhouse effect develops during a teacher education programme. NorDiNa, 5, 17-29.

Farmer, G. T., \& Cook, J. (2013). Climate Change Science: A Modern Synthesis: Volume 1-The Physical Climate (Vol. 1). Berlin, Germany: Springer Science \& Business Media. https:/ / doi.org/10.1007/978-94-007-5757-8

Feldman, A., Nation, M., Smith, G.G., \& Besalti, M. (2017). Teaching climate change science to high school students: Local place-based approach, web-based novel with computer games, and hands-on activities. In I. Levin \& D. Tsybulsky (eds.), Digital Tools and Solutions for Inquiry-Based STEM Learning, New York, NY: IGI Global, https:/ / doi.org/10.4018/978-1-5225-2528-8.ch002-5225-2528-8.ch002

Garris, R., Ahlers, R., \& Driskell, J. (2002). Games, motivation and learning: a research and practice model. Simulation \& Gaming, 33(4), 441-467. https: / / doi.org/10.1177/1046878102238607

Galindo-Gonzalez, S., Berry, L., Cox, C., Edwards, A., Ellingson, R., Feldman, A., . . Ryan, J. (2011). Florida Climate Change Education and Training: State University System Cooperative Plan. Retrieved from http:/ / floridaclimate.org/whitepapers/

Gayford, C. (2002). Controversial environmental issues: a case study for the professional development of science teachers. International Journal of science education, 24(11), 1191-1200. https:/ / doi.org/10.1080/09500690210134866

Gee, J. P. (2005). Learning by design: Good video games as learning machines. E-Learning, 2(1), 1-12. https:// doi.org/10.2304/elea.2005.2.1.5

Grbich, C. (2013). Qualitative data analysis: An introduction. Thousand Oaks, CA: SAGE.

Hallar, A. G., McCubbin, I. B., \& Wright, J. M. (2011). CHANGE: A place-based curriculum for understanding climate change at Storm Peak Laboratory, Colorado. Bulletin of the American Meteorological Society, 92(7), 909. https:/ / doi.org/10.1175/2011BAMS3026.1

Hasher, L., \& Zacks, R. T. (1979). Automatic and effortful processes in memory. Journal of Experimental Psychology: General, 3, 356-388. https:/ / doi.org/10.1037/0096-3445.108.3.356

Hilgard, E. R. (1980). The trilogy of mind: Cognition, affection, and conation. Journal of the History of the Behavioral Sciences, $\quad 16(2), \quad$ 107-117. https://doi.org/10.1002/1520-6696(198004)16:2<107::AIDJHBS2300160202>3.0.CO;2-Y

Herman, B. C., Feldman, A., \& Vernaza-Hernandez, V. (2015). Florida and Puerto Rico Secondary Science Teachers' Knowledge and Teaching of Climate Change Science. International Journal of Science and Mathematics Education, 1-21. https:/ / doi.org/10.1007/s10763-015-9706-6

Junyent, M. \& de Ciurana, A. M. G. (2008) Education for sustainability in university studies: a model for reorienting the curriculum, British Educational Research Journal, 34(6), 763-782. https:/ / doi.org/10.1080/01411920802041343

Keim, D., Mansmann, F., Schneidewind, J., Thomas, J., \& Ziegler, H. (2008). Visual Analytics: Scope and Challenges. In: Simoff, S.J., Böhlen, M.H., Mazeika, A. (eds.) Visual Data Mining. LNCS, 4404, 76-90. Springer, Heidelberg. https:/ / doi.org/10.1007/978-3-540-71080-6_6

Kosslyn, S. M. (2005). Mental images and the brain. Cognitive Neuropsychology, 22(3/4), 333-347. https:/ / doi.org/10.1080/02643290442000130

Kosslyn, S., Ball, T., \& Reiser, B. (1978). Visual images preserve metric spatial information: Evidence from studies of image scanning. Journal of Experimental Psychology. Human Perception and Performance, 4, 47-60. https:/ / doi.org/10.1037/0096-1523.4.1.47

Li, M. C., \& Tsai, C. C. (2013). Game-based learning in science education: a review of relevant research, Journal of Science Education and Technology, 22(6), 877-898. https:/ / doi.org/10.1002/1520-6696(198004)16:2<107::AIDJHBS2300160202>3.0.CO;2-Y

Liu, S., Roehrig, G., Bhattacharya, D., \& Varma, K. (2015). In-service teachers' attitudes, knowledge and classroom teaching of global climate change. Science Educator, 24(1), 12.

Leiserowitz, A., Maibach, E., Roser-Renouf, C., \& Smith, N. (2011). Global warming's six Americas, May 2011. Yale University and George Mason University. New Haven, CT: Yale 
Miles, M. B., Huberman, A. M., \& Saldana, J. (2014). Qualitative data analysis: A methods sourcebook. Thousand Oaks, CA: SAGE.

NGSS Lead States. (2013). Next Generation Science Standards: For States, by States. Washington, DC: The National Academies Press.

Prensky, M. (2003). Digital game-based learning. Computers in Entertainment (CIE), 1(1), 21-21. https:/ / doi.org/10.1145/950566.950596

Pruneau, D., Liboiron, L., Vrain, E., Gravel, H., Bourque, W., \& Langis, J. (2001). People's idea about climate change: A source of inspiration for the creation of educational programs. Canadian Journal of Environmental Education, 6, 121-138.

Schell, J. (2008). The art of game design: A book of lenses. New York, NY: CRC Press. https:/ / doi.org/10.1201/9780080919171

Smith, G. G. \& Besalti, M. (2018). Learning Climate Change Science with Computer Games in a Science Fiction Novel, Proceedings of ED-MEDIA 2018: World Conference on Educational Multimedia, Hypermedia $\mathcal{E}$ Telecommunications, Amsterdam, Netherlands.

Smith, G.G., Lou Y., Feldman, A., Wang, P. (2015, July). Science fiction novels with games for learning climate change science, Proceedings of the annual meeting of EduLearn, Barcelona, Spain.

Smith, L.A. \& Stern, N. (2011). Uncertainty in science and its role in climate policy. Philosophical transactions of the Royal Society A. 369: 124. https:/ / doi.org/10.1098/rsta.2011.0149

Sweller, J. (1994). Cognitive load theory, learning difficulty, and instructional design. Learning and Instruction, 4(5), 295-312. https:/ / doi.org/10.1016/0959-4752(94)90003-5

Vygotsky, L. (1987). Zone of proximal development. Mind in society: The development of higher psychological processes, 5291, 157.

Whittaker, T. (May 15, 2018). Hurricane Simulation, Retrieved from https:/ / scijinks.gov/hurricane-simulation/

Wise, S. B. (2010). Climate change in the classroom: Patterns, motivations, and barriers to instruction among Colorado science teachers. Journal of Geoscience Education, 58(5), 297-309. https:/ / doi.org/10.5408/1.3559695 


\section{APPENDIX A}

\section{Students' Beliefs About Climate Change Survey}

\begin{tabular}{|c|c|c|c|c|}
\hline & True (1) & $\begin{array}{l}\text { Probably } \\
\text { True (2) }\end{array}$ & $\begin{array}{l}\text { Probably } \\
\text { False (3) }\end{array}$ & False (4) \\
\hline A. Climate means average weather (1) & $\mathrm{O}$ & $\mathrm{O}$ & $\mathrm{O}$ & $\mathrm{O}$ \\
\hline B. Weather means average climate. (2) & $\mathrm{O}$ & $\mathrm{O}$ & $\mathrm{O}$ & $\mathrm{O}$ \\
\hline C. Climate often changes from year to year. (3) & $\mathrm{O}$ & $\mathrm{O}$ & $\mathrm{O}$ & $\mathrm{O}$ \\
\hline D. Weather often changes from year to year. (4) & $\mathrm{O}$ & $\mathrm{O}$ & $\mathrm{O}$ & $\mathrm{O}$ \\
\hline $\begin{array}{l}\text { E. The earth's climate has been pretty much the same for millions } \\
\text { of years. (5) }\end{array}$ & $\mathrm{O}$ & $\mathrm{O}$ & $\mathrm{O}$ & $\mathrm{O}$ \\
\hline $\begin{array}{l}\text { F. The temperature of the earth is significantly affected by the } \\
\text { gases that make up the atmosphere. (6) }\end{array}$ & $\mathrm{O}$ & $\mathrm{o}$ & $\mathrm{o}$ & $\mathrm{O}$ \\
\hline $\begin{array}{l}\text { G. The temperature of the earth is significantly affected by the sun. } \\
\text { (7) }\end{array}$ & $\mathrm{O}$ & $\mathrm{O}$ & $\mathrm{o}$ & $\mathrm{O}$ \\
\hline $\begin{array}{l}\text { H. The temperature of the earth is significantly affected by the } \\
\text { moon. (8) }\end{array}$ & $\mathrm{O}$ & $\mathrm{O}$ & $\mathrm{O}$ & $\mathrm{O}$ \\
\hline $\begin{array}{l}\text { I. The temperature of the earth is significantly affected by how } \\
\text { much dust there is in the atmosphere. (9) }\end{array}$ & $\mathrm{O}$ & $\mathrm{O}$ & $\mathrm{O}$ & $\mathrm{O}$ \\
\hline $\begin{array}{l}\text { J. The temperature of the earth is significantly affected by } \\
\text { earthquakes. (10) }\end{array}$ & $\mathrm{O}$ & $\mathrm{o}$ & $\mathrm{o}$ & $\mathrm{o}$ \\
\hline $\begin{array}{l}\text { K. The temperature of the earth is significantly affected by clouds. } \\
\text { (11) }\end{array}$ & $\mathrm{O}$ & $\mathrm{O}$ & $\mathrm{O}$ & $\mathrm{O}$ \\
\hline $\begin{array}{l}\text { L. The temperature of the earth is significantly affected by whether } \\
\text { the earth's surface is light or dark. (12) }\end{array}$ & $\mathrm{O}$ & $\mathrm{o}$ & $\mathrm{o}$ & $\mathrm{o}$ \\
\hline $\begin{array}{l}\text { M. The temperature of the earth is significantly affected by large } \\
\text { meteor impacts. (13) }\end{array}$ & $\mathrm{O}$ & $\mathrm{o}$ & $\mathrm{o}$ & $\mathrm{O}$ \\
\hline $\begin{array}{l}\text { N. The temperature of the earth is significantly affected by the } \\
\text { ocean. (14) }\end{array}$ & $\mathrm{O}$ & $\mathrm{O}$ & $\mathrm{O}$ & $\mathrm{O}$ \\
\hline $\begin{array}{l}\text { O. The temperature of the earth is significantly affected by large } \\
\text { volcanic eruptions. (15) }\end{array}$ & $\mathrm{O}$ & $\mathrm{o}$ & $\mathrm{o}$ & $\mathrm{o}$ \\
\hline $\begin{array}{l}\text { P. The atmosphere usually carries heat from the equator toward } \\
\text { the north and south poles. (16) }\end{array}$ & $\mathrm{O}$ & $\mathrm{o}$ & $\mathrm{o}$ & $\mathrm{O}$ \\
\hline $\begin{array}{l}\text { Q. The atmosphere usually carries heat from the north and south } \\
\text { poles toward the equator. (17) }\end{array}$ & $\mathrm{O}$ & $\mathrm{O}$ & $\mathrm{O}$ & o \\
\hline $\begin{array}{l}\text { R. The main way in which global warming will cause sea level to } \\
\text { rise is by melting ice near the north pole. (18) }\end{array}$ & $\mathrm{O}$ & $\mathrm{o}$ & $\mathrm{O}$ & $\mathrm{O}$ \\
\hline $\begin{array}{l}\text { S. The main way in which global warming will cause sea level to } \\
\text { rise is by melting ice near the south pole. (19) }\end{array}$ & $\mathrm{O}$ & $\mathrm{O}$ & $\mathrm{O}$ & $\mathrm{O}$ \\
\hline $\begin{array}{l}\text { T. The main way in which global warming will cause sea level to } \\
\text { rise is by warming the oceans. (20) }\end{array}$ & $\mathrm{O}$ & $\mathrm{O}$ & $\mathrm{O}$ & O \\
\hline
\end{tabular}

\section{http://www.ejmste.com}

